\title{
A introdução da interseccionalidade em Portugal: Repensar as políticas de igualdade(s)
}

The Introduction of Intersectionality in Portugal: Rethinking the Politics of

Equality(ies)

L'introduction de l'intersectionnalité au Portugal : repenser les politiques

d'égalité(s)

Alba Alonso

\section{OpenEdition}

\section{Journals}

Edição electrónica

URL: http://journals.openedition.org/rccs/1760

DOI: $10.4000 /$ rccs. 1760

ISSN: 2182-7435

\section{Editora}

Centro de Estudos Sociais da Universidade de Coimbra

Edição impressa

Data de publição: 1 Setembro 2010

Paginação: 25-43

ISSN: 0254-1106

\section{Refêrencia eletrónica}

Alba Alonso, «A introdução da interseccionalidade em Portugal: Repensar as políticas de igualdade(s) », Revista Crítica de Ciências Sociais [Online], 90 | 2010, colocado online no dia 15 outubro 2012, criado a 19 abril 2019. URL : http://journals.openedition.org/rccs/1760 ; DOI : 10.4000/rccs.1760 


\title{
ALBA ALONSO
}

\section{A introdução da interseccionalidade em Portugal: Repensar as políticas de igualdade(s)'}

\begin{abstract}
A literatura mais recente sobre políticas de igualdade tem prestado grande atenção à inserção da interseccionalidade nas políticas públicas, especialmente desde que a UE apostou em introduzir a nova agenda das desigualdades múltiplas. Este artigo segue outros estudos que abordam as reacções de diferentes Estados-membros a esta nova prioridade política europeia e analisa o caso português. Usando a tipologia apresentada por Hancock (2007), argumentará que este país inicia a transição para uma perspectiva múltipla, partindo da aprovação de novos planos e organismos em que as desigualdades nem sempre são tratadas de modo independente. Paralelamente, prestará atenção às peculiaridades demonstradas pela experiência de Portugal, tais como a aposta nos conselhos de participação ou no desenvolvimento de um modelo institucional diferenciado.
\end{abstract}

Palavras-chave: desigualdades múltiplas; interseccionalidade, igualdade, Portugal, políticas públicas.

\section{Introdução}

Durante as últimas décadas, os estudos de género passaram a considerar a sua combinação com outros tipos de critérios de diferença, como a classe, a raça ou a orientação sexual, sublinhando a relevância de todos eles para entender as desigualdades sofridas pelas mulheres. Ainda que este tipo de realidades fosse conceptualizado de diversas maneiras (dupla discriminação, discriminações compostas, etc.), um dos termos que conta com maior aceitação é o de interseccionalidade. A metáfora da intersecção foi introduzida por Kimberlé Crenshaw para dar ênfase à existência de vários eixos de desigualdade (raça, etnia, género, etc.) que, tal como avenidas numa grande cidade, transcorrem de modo independente, contando no entanto com múltiplas e variadas intersecções (Crenshaw 1989, 1993, 2002). Os indivíduos situados

\footnotetext{
${ }^{1}$ Gostaria de agradecer a todas as pessoas que aceitaram ser entrevistadas para a realização deste trabalho. Este trabalho foi realizado no âmbito do Projecto QUING (Quality in Gender+ Equality Policies), financiado pelo VI Programa-Quadro da Comissão Europeia. Para mais informação, consultar www.quing.eu.
} 
entre eixos diversos (mulheres negras, lésbicas, etc.) sofreriam a desigualdade de modo único e qualitativamente diferente, impossível de ser analisado a partir de uma mera soma de categorias. Para além de explorar as consequências da sua situação diferenciada, a literatura começou a salientar a necessidade de as políticas públicas tomarem também em consideração a interseccionalidade. O objectivo não é só detectar os efeitos das desigualdades múltiplas, mas também estudar a forma como os poderes públicos podem responder à sua existência. Em geral, considera-se que, para aplicar políticas mais justas e inclusivas, é necessário ter em conta que nem homens nem mulheres são grupos homogéneos e, como tal, se vêem afectados por mais de um tipo de discriminação (Lombardo e Verloo, 2009a, 2009b; Squires, 2005). Esta nova perspectiva pretende superar uma dupla limitação, comum a muitas das políticas aplicadas. Até aqui, estas manifestaram tendência tanto para a superinclusão - isto é, no sentido de tratar um problema pertencente a um determinado grupo como se fosse um problema geral -, como para a subinclusão, ou seja, abordar um problema geral como se só atingisse um grupo concreto (Crenshaw, 2002). As limitações de ambas demonstraram a incapacidade de reconhecer a experiência de indivíduos que se encontram na intersecção de grupos vários.

Assim, propõem-se novas linhas de análise da interseccionalidade no desenvolvimento de políticas públicas, especialmente aquelas relativas à igualdade. As questões centrais colocadas são: em primeiro lugar, será que as políticas públicas reconhecem que as desigualdades estão interligadas e que uma pessoa pode sofrer mais do que uma ao mesmo tempo? Se assim for, até que ponto podemos dizer que esta nova perspectiva está a ser institucionalizada? O crescente interesse neste tema tem muito que ver com a actual aposta da União Europeia na luta contra as desigualdades múltiplas. Por um lado, a UE ampliou a legislação em matéria de igualdade através da aprovação do Tratado de Amesterdão (que protege contra seis eixos de discriminação diferentes) e das Directivas 2000/43/CE e 2000/78/CE, relativas à igualdade de tratamento no emprego e à discriminação étnica e racial (Bell, 2008). Por outro lado, modificou a estrutura institucional que se ocupa das questões de desigualdade, optando por criar um só organismo orientado para todos os eixos de discriminação. Estas duas orientações apontam para o desenvolvimento de um modelo integrado, isto é, sustentado na presença de uma legislação e de um organismo executivo que aborde todas as questões da desigualdade. O intuito principal não é só o de abordar as desigualdades múltiplas, mas também acabar com a hierarquia tradicional entre eixos que garante maior protecção para alguns em detrimento de outros (Niessen e Cormack, 2004). 
Tanto a presença de uma nova normativa vinculativa (hard law) como a introdução do modelo integrado resultaram em notáveis modificações a nível estatal (ver, por exemplo, Squires, 2007; Mabbet, 2005), dando lugar à aprovação de novas leis antidiscriminação e a transformações na arquitectura institucional. A literatura não permaneceu alheia a esta mudança de perspectiva e tem tentado estudar o impacto, tanto da própria estratégia europeia em matéria de desigualdade, como do debate geral existente em torno da interseccionalidade, nas políticas dos diferentes países.

Dado que ainda não conta com uma análise detalhada, ${ }^{2}$ este artigo centra-se no caso português e expõe as suas especificidades. Seguindo a tipologia definida por Hancock (2007), argumentará que Portugal está em vias de transição da tradicional perspectiva unitária, que pressupõe a existência de políticas diferenciadas para cada desigualdade (cf. secção 2.1), em direcção a uma perspectiva múltipla, em que, pela primeira vez, se considera que estas podem ser complementares (cf. secção 2.2). Esta nova perspectiva, porém, não significa a aposta na criação de um só organismo e uma só legislação, tal como acontece na estratégia europeia. Muito pelo contrário, ela desenvolve um modelo próprio que se fundamenta na manutenção de políticas especializadas e na aposta no aumento da coordenação entre os organismos de igualdade já existentes. Para além disso, este país conta com uma longa tradição em matéria de criação de conselhos participativos; à luz da literatura nesta matéria, esta especificidade pode abrir oportunidades para introduzir uma perspectiva interseccional (secção 2.3), sendo a própria relação entre as desigualdades que permite a colocação do que Hancock denomina como uma questão empírica aberta (open empirical question). A recolha destas e de outras particularidades fundamenta-se na análise da legislação e dos planos de igualdade mais recentes, assim como na realização de diversas entrevistas exploratórias com decisores/as políticos/as e com membros de organizações da sociedade civil. ${ }^{3}$ Estes dados permitiram um entendimento mais aprofundado da introdução da interseccionalidade nas políticas portuguesas.

\footnotetext{
${ }^{2}$ Em casos excepcionais, podemos encontrar análises que expõem a interacção dinâmica entre eixos (ver, por exemplo, Santos, 2004; Albuquerque, 2005) ou a incorporação de mais de uma desigualdade nas políticas públicas (ver, por exemplo, Cardoso, 2000).

${ }^{3}$ Realizaram-se seis entrevistas que incluíram representantes dos principais organismos de igualdade, assim como de organizações da sociedade civil que fazem parte dos diversos conselhos de participação do governo português e que têm que ver com desigualdades diferentes. Todas tiveram lugar em Lisboa, de 2 a 4 de Março de 2009, e permitiram saber mais sobre o funcionamento deste tipo de estruturas.
} 


\section{As políticas de igualdade em Portugal: em direcção a uma ordem de trabalhos orientada para a visibilidade das desigualdades múltiplas?}

\subsection{Os organismos de promoção da igualdade e a legislação contra a discriminação} Até há pouco tempo, e tal como em muitos outros países (ver, por exemplo, Squires, 2007; Bustelo, 2009), Portugal aplicava um conjunto de políticas para a promoção da igualdade a partir do que Hancock denominaria como uma perspectiva puramente unitária (Hancock, 2007: 67). Isto significa que os eixos de desigualdade eram abordados de modo independente e tratados por organismos, leis e políticas plenamente diferenciados. Para além disso, e em linha com outros exemplos, existia um certo nível de hierarquia baseado num tratamento mais desenvolvido e pré-estabelecido de alguns destes eixos de discriminação, nomeadamente a discriminação por sexo, deficiência e raça. ${ }^{4}$

No que diz respeito à legislação, existem em Portugal dois grandes "guarda-chuvas" antidiscriminação: a Constituição e o Código do Trabalho. A primeira estabelece no seu artigo 13 que nenhum/a cidadão/ã poderá ser discriminado/a pela sua ascendência, sexo, raça, língua, país de origem, religião, convicções políticas ou ideológicas, educação, situação económica, condição social ou orientação sexual. Este último critério foi acrescentado em 2004, convertendo Portugal num dos primeiros países que protege constitucionalmente contra este tipo de discriminação. Numa linha similar, o Código do Trabalho abrange actualmente um número máximo de 19 critérios diferentes, incluindo aqueles oriundos da transposição das directivas europeias em matéria de igualdade de tratamento. ${ }^{5}$ Apesar da existência destas normas-quadro, uma análise mais detalhada da normativa permite notar a existência de uma certa diferenciação e hierarquia no tratamento dos vários eixos de desigualdade. Assim, a deficiência, o género e a raça, os mais destacados, contam com legislação própria, que, no caso dos dois primeiros, começa a ser aprovada desde a década de $70,{ }^{6}$ ocorrendo em simultâneo com outros países europeus. Ainda que incorporada posteriormente, a discriminação por razões de raça e etnia desfruta também de cobertura normativa

\footnotetext{
${ }^{4}$ Usarei o termo raça para me referir ao que nas políticas e leis portuguesas inclui raça, nacionalidade, cor e etnia.

5 Ver a última versão na Lei 7/2009 de 12 Fevereiro, que aprova o Código do Trabalho.

${ }^{6}$ Ver, por exemplo, a Lei 6/1971, de 8 Novembro, que aprova as bases relativas à reabilitação e à integração social dos indivíduos com deficiências ou a Lei 392/1979, de 20 Setembro, que garante a igualdade de oportunidades e a igualdade de tratamento para as mulheres no emprego e no trabalho.
} 
significativa, incluindo, entre outras, a Lei 134/1999, aprovada antes da própria Directiva europeia. ${ }^{7}$

Os organismos de promoção da igualdade reproduzem fielmente a perspectiva unitária e essencialmente hierárquica anunciada pela legislação. As desigualdades baseadas no género e na deficiência contam com um organismo próprio desde os anos 70. No caso do primeiro, encontramos o aparecimento precoce do Grupo de Trabalho para a Participação das Mulheres na Vida Social e Económica, logo em 1970. A vontade de realizar algumas reformas modernizadoras por parte do governo ou a presença de policy advocacies dentro do mesmo foram assinaladas como alguns dos elementos que explicam este inesperado nascimento do feminismo de Estado em Portugal (Valiente, 1998). Estas peculiaridades distinguem-no de outros países onde as reivindicações do movimento feminista ou a presença de governos social-democratas tiveram maior relevância. Este aparecimento prematuro teve continuidade com a criação, em 1977, da Comissão da Condição Feminina. Tanto a realização da $1 .{ }^{a}$ Conferência Mundial sobre a Mulher organizada pela ONU, como a vontade modernizadora do recém-instaurado regime democrático, são apontados como factores explicativos (Valiente, 1998; Tavares, 2000). As subsequentes reformas realizadas neste organismo de promoção da igualdade, assim como a criação, em 1979, da Comissão para a Igualdade no Trabalho e no Emprego (CITE), um órgão de cariz especializado, dão uma ideia da progressiva consolidação do feminismo de Estado e das políticas de género no país, assim como o carácter privilegiado deste eixo. A recente criação da actual Comissão para a Cidadania e a Igualdade de Género (CIG), representou, de facto, mais um avanço em quase quarenta anos de história.

Os organismos devotados à promoção da igualdade por razões de deficiência contam também com um desenvolvimento notável. Criado em 1971, o Secretariado Nacional para a Reabilitação tinha como objectivo integrar socialmente pessoas com deficiência. ${ }^{8}$ Esta estratégia institucional tão precoce entende-se quando enquadrada no âmbito da atenção prestada a este grupo de pessoas por um incipiente Estado Providência, em vias de desenvolver um sistema de apoios sociais ainda embrionário (Capucha et al., 2005). Longe de perder importância, e apesar de múltiplas reformas, este órgão viu-se progressivamente consolidado. Hoje em dia, o Instituto Nacional para a

\footnotetext{
${ }^{7}$ Apesar da existência da Lei 134/1999, que proíbe a discriminação baseada na raça, a cor, a nacionalidade ou a origem étnica, a Directiva 2000/43/CE foi posteriormente transposta pela Lei 18/2004, de 11 de Maio.

${ }^{8}$ Ao contrário de outros países, em Portugal o termo "deficiência" ainda continua a ser de uso comum.
} 
Reabilitação (INR), criado em 2007, desenvolve a sua acção no âmbito da integração das pessoas com deficiência na sociedade e no mercado de trabalho.

As políticas de promoção da igualdade baseadas em raça, etnia, cor da pele e nacionalidade tiveram desenvolvimento posterior. Tanto a legislação como os organismos públicos de promoção da igualdade desenvolveram-se nos anos 90, em paralelo com a intensificação da imigração em Portugal (Abranches, 2008). Este tipo de políticas ganhou rapidamente protagonismo, contando na actualidade com organismos análogos aos das questões de género e de deficiência. Neste caso, optou-se por uma dupla estratégia. Em 1996, foi criado o Alto Comissariado para a Imigração e as Minorias Étnicas (ACIME) como instituição encarregada de promover o diálogo social com as comunidades imigrantes. Pouco depois, em 1999, surge a Comissão para a Igualdade e contra a Discriminação Racial, concebida como um órgão independente que acompanha as queixas em matéria de discriminação e que faz o seguimento das políticas governamentais. A sua composição mista, tanto por representantes da sociedade civil como das instituições, não permite, no entanto, um elevado grau de independência (Malheiros, 2007). A progressiva ampliação de ambos os órgãos, e especialmente do Alto Comissariado que, a partir de 2007, passou a ser denominado Alto Comissariado para a Imigração e o Diálogo Intercultural (ACIDI), deve ser destacada. Ainda que tivesse começado por ser um órgão de carácter unipessoal, com recursos e atribuições limitados, hoje em dia é uma instituição semelhante às existentes para a promoção da igualdade de sexo e para a integração de pessoas com deficiência.

Apesar da existência de outros órgãos especializados, como o Instituto Português da Juventude ou a Comissão para a Liberdade Religiosa, os três eixos acima mencionados contam, sem dúvida, com um desenvolvimento privilegiado, manifestado em amplos recursos e uma longa tradição. Todos eles põem em evidência, além disso, a existência de uma clara aposta em abordar as desigualdades de modo independente, desenvolvendo leis, planos e programas diferenciados. A presença desta perspectiva unitária vê-se também ilustrada na análise discursiva realizada no âmbito do projecto QUING, em que se explorou a presença de interseccionalidade em documentos chave das políticas públicas no período 1995-2007 (Alonso e Nunes, 2008). A principal conclusão foi que pouca atenção era prestada à presença de desigualdades múltiplas, excepto em eventuais documentos mais recentes. Todas as observações deixam clara a prevalência de uma perspectiva unitária em que não existe lugar para uma análise das intersecções entre desigualdades, colocando Portugal em sintonia com outros países estudados, como, por exemplo, a vizinha Espanha (ver Bustelo, 2009). 


\subsection{Novos planos e organismos de coordenação: repensar as políticas de igualdade(s)}

As políticas e linhas de trabalho desenvolvidas nos últimos anos, especialmente desde 2007, têm vindo a matizar a presença de uma perspectiva puramente unitária. O gradual reconhecimento de que as desigualdades nem sempre aparecem de modo independente e sofrem múltiplas intersecções abre a possibilidade de falar, pela primeira vez, da presença do que Hancock denomina uma perspectiva múltipla. Nela se toma em linha de conta a combinação de desigualdades, se bem que ainda centrada num cruzamento estático de abordagens de certos grupos interseccionais com certas políticas (Hancock, 2007: 67). Nota-se a presença desta nova perspectiva tanto no plano institucional, por exemplo, nas últimas reformas dos organismos de promoção de igualdade, como na perspectiva adoptada pelos planos de acção mais recentes.

No plano institucional, o ano de 2007 significou a reforma dos três grandes organismos de igualdade: o INR (orientado para a deficiência), o ACIDI (orientado para a raça) e a CIG (orientada para questões de género). Apesar de todos eles se terem orientado para a interseccionalidade, as mudanças neste último organismo são as de maior interesse. Nesse ano dá-se a substituição da antiga CIDM, Comissão para a Igualdade e os Direitos das Mulheres, pela actual Comissão para a Cidadania e a Igualdade de Género. A inclusão do termo "género" em substituição da anterior menção relativa às mulheres valoriza, pela primeira vez, o cariz estrutural das desigualdades e o papel dos homens como parte do problema e da solução. Para além disso, deve destacar-se a referência ao termo "cidadania", associado ao actual interesse em abordar as desigualdades múltiplas sofridas pelas mulheres. Dado o carácter transversal do género, ele pode interagir com outros eixos de discriminação, como a deficiência, a orientação sexual ou a etnia, causando situações de ainda maior desvantagem para as mulheres. Consequentemente, é necessário ter estes eixos em linha de conta nas próprias políticas de género, assim como considerar a assimetria entre mulheres e homens quando aplicamos outras políticas de igualdade. A valorização das possíveis intersecções entre eixos torna-se especialmente visível na actual composição do Conselho Consultivo da CIG. Na secção de ONG que é parte integrante deste organismo, encontram-se representadas organizações correspondentes a diferentes tipos de desigualdade, para além das relativas ao género. A sua inclusão, em 2007, representou uma profunda mudança num conselho antes essencialmente integrado por organizações de mulheres. A intenção era ampliar as possibilidades de adoptar uma perspectiva mais interseccional nas políticas relativas à igualdade (voltaremos a isto 
na secção 2.3). Finalmente, é necessário mencionar que a reforma da CIG inclui um outro eixo de desigualdade que não fora anteriormente coberto. Trata-se da orientação sexual, que, daqui em diante, fará parte da agenda política desta mesma instituição.

A tímida inclusão da interseccionalidade nas linhas de trabalho de alguns organismos de igualdade, nomeadamente da CIG, vê-se reflectida nos planos de actuação mais recentes. Enquanto os anteriores eram essencialmente cegos à existência de intersecções entre eixos e apostavam numa perspectiva puramente unitária (Alonso e Nunes, 2008), os vigentes deixam claro que existe um crescente interesse em abordar as desigualdades múltiplas (tabela 1). Esta vontade manifesta-se em algumas ocasiões de modo explícito. Assim, por exemplo, o III Plano Nacional de Igualdade: Cidadania e Género 2007-2010 estabelece que "as situações de discriminação múltipla exigem uma particular atenção atendendo às situações de desigualdade de oportunidades e discriminação que as mulheres enfrentam cumulativamente em função da raça, do território de origem, da religião, da deficiência, da idade ou da orientação sexual". Além de referências como esta, os planos incluem também uma abordagem implícita das desigualdades múltiplas, com acções que atingem colectivos concretos. Esse é o caso das questões orientadas para o género que se incluem, por exemplo, nas actividades

TABELA 1 - Tipo de desigualdade/s incluída/s por plano ${ }^{9}$

\begin{tabular}{|l|l|}
\hline \multicolumn{1}{|c|}{ Plano } & \multicolumn{1}{|c|}{ Desigualdade/s } \\
\hline $\begin{array}{l}\text { III Plano Nacional de Igualdade: Cidadania e } \\
\text { Género 2007-2010. }\end{array}$ & $\begin{array}{l}\text { género + raça, território de origem, religião, } \\
\text { deficiência, idade ou orientação sexual }\end{array}$ \\
\hline Plano para a Integração dos Imigrantes & raça/etnia/cor/religião + género \\
\hline $\begin{array}{l}\text { I Plano de Acção para a Integração de Pes- } \\
\text { soas com Deficiências ou Incapacidade } \\
\text { 2006-2009 }\end{array}$ & deficiências \\
\hline $\begin{array}{l}\text { III Plano Nacional para a Inclusão Social } \\
\text { 2006-2008 }\end{array}$ & $\begin{array}{l}\text { classe + idade, género, cidadania, deficiência } \\
\text { ou etnia }\end{array}$ \\
\hline $\begin{array}{l}\text { Plano Nacional para o Ano Europeu de Igual- } \\
\text { dade de Oportunidades para Todos }\end{array}$ & $\begin{array}{l}\text { género + idade + orientação sexual + etnia + } \\
+ \text { religião + crenças + deficiências }\end{array}$ \\
\hline I Plano contra o Tráfico de Pessoas & classe + género + idade + raça + cidadania \\
\hline Programa contra a Mutilação Genital & género + idade, raça, cidadania, religião \\
\hline
\end{tabular}

Fonte: elaboração própria

${ }_{9}$ Os eixos principais encontram-se em itálico. 
inscritas nos planos relativos à integração dos/as imigrantes ou à inclusão social. Em geral, todos eles adoptam uma perspectiva múltipla, baseada essencialmente na consideração de certos grupos interseccionais. Esta inclusão não impede, no entanto, que a maioria continue a estar organizada em torno de um eixo privilegiado, facto que é previsível se tivermos em conta que, até há pouco tempo, as intersecções entre desigualdades eram usualmente ignoradas.

Além de incluírem novos objectivos, estes planos são também interessantes do ponto de vista institucional. Tal como já foi referido, e apesar da recente introdução por parte da UE do denominado modelo integrado, os organismos de igualdade portugueses funcionam de modo independente desde o seu nascimento. Referimos também que este modelo teve um impacto relevante nos Estados-membros - e não membros -, que, em muitos casos, apostaram igualmente em estabelecer normativas e instituições únicas para todas as desigualdades (Bell, 2008; Niessen e Cormack, 2004). A título de exemplo, é o caso da criação na Grã-Bretanha da Commission for Equality and Human Rights (Squires, 2007, 2008b), da Equality and AntiDiscrimination Ombud na Noruega (Skjeie e Langvasbraten, 2009) ou da Fundamental Rights Agency criada pela própria UE ${ }^{10}$ (Lombardo e Verloo, 2009a). Em Portugal, apesar de tudo, não existe intenção de modificar a actual arquitectura institucional. Os novos planos de igualdade propõem aqui uma solução intermédia. Longe de apostar num só órgão, optam por manter os existentes e, paralelamente, criar diversas estruturas de coordenação que pretendem aprofundar o trabalho conjunto das instituições existentes. Assim, cada um dos planos de igualdade conta com um organismo interdepartamental no qual estão incluídos várias secções governamentais e órgãos de igualdade, especialmente a CIG e o ACIDI, que fazem parte de quase todos eles. ${ }^{11}$ Favorece-se deste modo a coordenação entre os diversos planos e acções, dando lugar a uma densa "rede" de políticas. Facilita-se também a abordagem das intersecções entre desigualdades, que, como vimos, começa a ser um dos objectivos dos planos mais recentes. Provavelmente, esta original arquitectura institucional surge favorecida pela tradição

\footnotetext{
${ }_{10}$ Apesar da sua criação, a UE continua a manter o European Institute for Gender Equality.

${ }^{11}$ As estruturas interdepartamentais existentes são as seguintes: Secção Interministerial do Conselho Consultivo da CIG; Comissão Interministerial para as Políticas de Juventude, dependente do Ministro da Presidência; Estrutura de Missão para o plano relativo ao Ano Europeu para a Igualdade de Oportunidades para Todos; Grupo de Trabalho e Comissão Interministerial do Plano Nacional para a Inclusão Social; Comissão Interministerial do Plano para a Integração dos Imigrantes; Comissão Técnica do Plano contra o Tráfico de Pessoas; Grupo de Trabalho Intersectorial do Programa contra a Mutilação Genital; e Grupo Interdepartamental do Plano de Ação para a Integração de Pessoas com Deficiências ou Incapacidade 2006-2009.
} 
existente neste país de situar os organismos de igualdade sob a alçada da Presidência do Conselho de Ministros. ${ }^{12}$ Isto permite a estes organismos não só desfrutar de uma posição privilegiada relativamente aos restantes departamentos governamentais, mas também manter um contacto mais contínuo, construindo, assim, pontes entre as diferentes políticas de igualdade.

Como vemos, Portugal tem a peculiaridade de desenvolver um modelo institucional intermédio para abordar as desigualdades múltiplas. Nem segue o modelo europeu criando um organismo único (modelo integrado), nem mantém os órgãos existentes como totalmente independentes (modelo separado). A estratégia foi mais a de desenvolver uma "terceira via" baseada no fortalecimento dos "velhos" organismos de igualdade e na criação de diversas estruturas de coordenação, lideradas por estes mesmos organismos. Este modelo, que podemos aqui denominar de coordenado, desafia a literatura existente, que tende a abordar a arquitectura institucional a partir de uma perspectiva dicotómica - modelo integrado versus modelo separado - e que identifica o modelo integrado como a única via para implementar a interseccionalidade. O caso português faz então surgir uma nova questão: será que se pode evoluir para a interseccionalidade sem criar um organismo único de igualdade?

\subsection{Sociedade civil e conselhos participativos: limites e potencialidades da inter- seccionalidade}

A recente introdução de uma perspectiva múltipla situa as políticas portuguesas, apesar de tudo, longe de uma perspectiva ou de uma abordagem interseccional. Segundo a define Hancock, uma abordagem interseccional ultrapassaria o reconhecimento de certos grupos interseccionais em certas políticas. Mais do que isso, consideraria que as desigualdades são mutuamente constitutivas e, logo, não podem ser abordadas de modo independente (Hancock, 2007: 74). Paralelamente, obrigaria a ter em linha de conta todas as possíveis combinações de tipos de desigualdade em todas as políticas, levando a um entendimento da interseccionalidade como uma questão empírica aberta (open empirical question). Mesmo com esta limitação, o caso português oferece a possibilidade de explorar a presença de certos aspectos que têm sido considerados como facilitadores, quando não requisitos, de uma perspectiva interseccional. Tal é o caso do envolvimento da sociedade civil no processo de elaboração das políticas, o qual, juntamente

12 Os órgãos de igualdade situam-se, desde a sua criação, sob a tutela da Presidência do Conselho de Ministros, com excepção do Instituto Nacional da Reabilitação, que sempre fez parte do Ministério de Trabalho e Assuntos Sociais, e da Comissão para a Igualdade e Direitos das Mulheres, que esteve incluída nesse mesmo ministério durante um breve período de tempo. 
com a criação de bases de dados ou a existência de sistemas de protecção de direitos, é um dos aspectos mais mencionados pela literatura. Entre as razões que explicam este interesse pela participação da sociedade civil encontra-se, em primeiro lugar, o facto de a interseccionalidade, além de ampliar a agenda política, também pressupor um desafio para as políticas de igualdade já existentes. Assim, a sua inclusão tem gerado um certo nível de competição entre organizações e instituições que representam desigualdades diferentes (Rolandsen, 2008; Lombardo e Verloo, 2009a), reproduzindo o que Martínez denominou uma opression olympics (apud Hancock, 2007: 68). A inclusão da sociedade civil nestes organismos aparece, então, como uma maneira adequada de canalizar essa tensão subjacente. Também se apontou que esta inclusão pode ajudar a diminuir o nível de essencialismo com o qual se abordam as desigualdades, pondo em questão as hierarquias internas das próprias organizações sociais e apagando as fronteiras entre os/as insiders e os/as outsiders (Squires, 2008a; Crenshaw, 1993). Finalmente, e de um ponto de vista mais pragmático, também se destacou a sua utilidade como um meio para conseguir mais informação sobre as desigualdades múltiplas (Lombardo e Verloo, 2009a; Yuval-Davis, 2006; Donaghy, 2004). Foi, de facto, a própria UE que recomendou em diversas ocasiões a necessidade de incluir os denominados "especialistas através da experiência" no processo de elaboração das políticas. ${ }^{13}$

Portugal oferece a possibilidade de explorar a potencial contribuição do envolvimento da sociedade civil para a introdução de uma perspectiva interseccional, visto que este país conta com uma longa tradição na criação de órgãos participativos, que acompanham os respectivos organismos de igualdade desde o seu nascimento. Como já foi referido, a CIG e o INR contam, desde 1977, com um Conselho Consultivo - secção de ONG e um Conselho Nacional para a Reabilitação e a Integração das Pessoas com Deficiência, ${ }^{14}$ respectivamente. Algo semelhante ocorre com o Conselho Nacional da Juventude, ${ }^{15}$ do IPJ, e o Conselho Consultivo para os Assuntos da Imigração, correspondente ao ACIDI, ambos criados em paralelo com os seus respectivos organismos. ${ }^{16}$ Os planos mais recentes, nomeadamente os relativos à inclusão social e ao Ano Europeu de Igualdade de Oportunidades para Todos, contam também com os seus respectivos órgãos participativos. Esta é, sem dúvida, uma característica peculiar das políticas de igualdade portuguesas, que as diferencia de muitos outros casos em que a sociedade

\footnotetext{
13 Ver, por exemplo, o European Action Program Against Discrimination (2001-2006).

${ }^{14}$ Criado pelo Decreto-lei 346/77, de 20 de Agosto.

${ }^{15}$ Inicialmente criado pelo Decreto-lei 333/93, de 29 de Setembro.

${ }_{16}$ Decreto-lei 39/98, de 27 de Fevereiro.
} 
civil carece de mecanismos de participação formais e estáveis que lhe permitam contribuir para o processo de elaboração das políticas. Não obstante, deve-se notar que, segundo algumas vozes, esta peculiaridade está provavelmente relacionada com a tradição corporativista proveniente do Estado Novo, ${ }^{17}$ que implicava a incorporação e inclusive a criação de grupos sociais por parte do Estado (Nicholls, 2007). Este tipo de precedentes, juntamente com a perspectiva top-down que costuma predominar na elaboração das políticas portuguesas (Ferreira, 1998), determina que este tipo de organismos deve ser considerado mais como incorporativo do que como realmente consultivo (Nicholls, 2007). Isto significa que os grupos sociais participantes não têm uma influência real sobre o processo de tomada de decisões, já que é raro submeter-se um texto legal ou um plano a um verdadeiro processo de consulta.

Apesar do seu impacto limitado, os conselhos participativos contribuíram para estabelecer laços com a sociedade civil e desenvolver um modelo institucional peculiar. Assim o evidenciam, por exemplo, os estudos referentes ao Conselho Consultivo da CIG, que dão a conhecer a contribuição da sua secção de ONG para o fortalecimento do movimento de mulheres em Portugal, especialmente durante as décadas de 70 e 80 , quando facilitou o estabelecimento de contactos e o desenvolvimento de relações de cooperação (Tavares, 2000). Todavia, este nível de sinergia decresceu nos anos 90, quando o alargamento da secção de ONG permitiu a entrada de diversas organizações não vinculadas nem ao movimento de mulheres nem ao feminista (Tavares, 2000; Bento, 1998). Contudo, o conselho permaneceu sempre activo e as ONG continuam hoje a colaborar na implementação de múltiplas acções, mantendo viva a longa tradição em matéria de parcerias. O Conselho Consultivo para os Assuntos da Imigração, pela sua parte, tem a particularidade de escolher os representantes da sociedade civil mediante eleições directas, o que garante um especial nível de envolvimento das organizações sociais e constitui uma autêntica raridade a nível internacional. Pretende-se, assim, que as políticas sejam elaboradas não só para os/as imigrantes mas também com os/as imigrantes. Finalmente, vale a pena mencionar a contribuição dos novos organismos participativos vinculados a planos de recente aprovação. Sirva como exemplo o Fórum Não-governamental para a Inclusão Social, criado em 2006, com o objectivo de possibilitar a colaboração da sociedade civil na concepção, aplicação e avaliação do plano nacional. Como resultado, o terceiro e quarto planos

${ }_{17}$ Para uma descrição pormenorizada do corporativismo português, ver, por exemplo, Schmitter (1975). 
relativos à inclusão social contam já com contribuições de diversas organizações, constituindo um dos poucos documentos públicos submetidos a um processo de consulta de relevo. Além disso, a constituição do Fórum deu lugar à criação de uma rede de organizações muito activa, que começa a desenvolver um trabalho contínuo e independente.

Além de serem interessantes pela sua contribuição concreta para a construção de laços entre a sociedade civil e as instituições públicas, estes conselhos participativos poderiam também sê-lo do ponto de vista da interseccionalidade. Tal aconteceria se na sua composição estivessem presentes organizações que representassem desigualdades diferentes. Deste modo, vale a pena perguntar: será que há uma clara intenção de incluir grupos que representam eixos diversos? A ser assim, a composição dos conselhos terá sido modificada para abordar as desigualdades múltiplas? Relativamente ao primeiro aspecto, pode observar-se que a composição dos diferentes conselhos reproduz parcialmente o leque de desigualdades abordadas pelos planos e organismos de que procedem (Tabela 2). Pode, inclusive, desenhar-se um continuum entre aqueles que aplicam uma clara perspectiva unitária (INR), representando um único eixo, aqueles que mostram uma

TABELA 2 - Principais tipos de desigualdade representadas segundo o conselho participativo

\begin{tabular}{|l|l|}
\hline \multicolumn{1}{|c|}{ Conselho } & \multicolumn{1}{c|}{ Desigualdades } \\
\hline $\begin{array}{l}\text { Secção de ONG do Conselho Consultivo } \\
\text { (CIG) }\end{array}$ & $\begin{array}{l}\text { género + cidadania + orientação sexual + } \\
\text { +deficiência + idade + religião + identi- } \\
\text { dades interseccionais }\end{array}$ \\
\hline $\begin{array}{l}\text { Conselho Consultivo } \\
\text { (ACIDI) }\end{array}$ & cidadania/etnia/raça + género + classe \\
\hline $\begin{array}{l}\text { Conselho Nacional para a Reabilitação e a Inte- } \\
\text { gração das Pessoas com Deficiências } \\
\text { (INR) }\end{array}$ & deficiências \\
\hline $\begin{array}{l}\text { Conselho Nacional da Juventude } \\
\text { (IPJ) }\end{array}$ & idade + identidades interseccionais \\
\hline $\begin{array}{l}\text { Fórum Não-Governamental para a Inclusão Social } \\
\text { (Ministério de Trabalho e Segurança Social) }\end{array}$ & $\begin{array}{l}\text { género + cidadania + deficiências + } \\
+ \text { etnia + idade }\end{array}$ \\
\hline $\begin{array}{l}\text { EMAEIOT - Estrutura de Missão para o Ano } \\
\text { Europeu para a Igualdade de Oportunidades para } \\
\text { Todos } \\
\text { (CIG) }\end{array}$ & $\begin{array}{l}\text { género + cidadania + deficiências + } \\
+ \text { etnia + idade + orientação sexual + } \\
+ \text { religião + identidades interseccionais }\end{array}$ \\
\hline
\end{tabular}


ligeira perspectiva múltipla (ACIDI e IPJ) e, finalmente, aqueles nos quais é evidente a aposta em incluir uma ampla variedade de organizações (CIG, FNGIS, EMAEIOT). Não é por acaso, portanto, que os planos que mostravam maior interesse por abordar as desigualdades múltiplas são os que também abriram os seus órgãos participativos a ONG especializadas em desigualdades diferentes, e inclusive em identidades interseccionais (mulheres ciganas, mulheres imigrantes, etc.). É especialmente relevante o caso da CIG, que, como já mencionámos, reformou recentemente o seu conselho consultivo com o fim de ampliar o leque de eixos representados. Assim, em linha com a nova agenda referente à luta contra as desigualdades múltiplas sofridas pelas mulheres e contra a discriminação por razão de orientação sexual, o seu conselho consultivo passou a integrar organizações relativas ao género, à etnia, às deficiências, à idade, à religião, à orientação sexual e às identidades interseccionais. Pretende-se assim captar melhor o modo como estes eixos afectam as mulheres de modo diferenciado.

Dado que, como já argumentámos anteriormente, a ampliação da agenda política da igualdade causa por vezes um certo nível de resistência, como são avaliados estes organismos pela sociedade civil? E a sua extensão? Considera-se esta uma oportunidade ou uma ameaça? Em primeiro lugar, a reforma da secção de ONG da CIG, um dos organismos de participação mais antigos, provocou certa controvérsia, dado que levou a que associações de mulheres com uma longa tradição neste organismo deixassem de fazer parte dele. Argumentou-se que, uma vez mais, a secção de ONG perdia a sua perspectiva feminista, evoluindo em direcção a políticas para as mulheres que se faziam sem as próprias mulheres. ${ }^{18}$ Estas críticas unem-se às acusações de instrumentalização e neutralização do movimento de mulheres por parte das instituições, que utilizariam o conselho participativo como um meio para manter certos temas fora da agenda (Bento, 1998; Amâncio, 1998). A realização de várias entrevistas de cariz exploratório permitiu aprofundar o nosso entendimento sobre a opinião da sociedade civil a respeito deste e de outros órgãos participativos, assim como da sua composição heterogénea. Ainda que exista um claro consenso sobre o limitado impacto destes conselhos na elaboração das políticas, estes são em geral avaliados de modo positivo. Na realidade, são vistos como um meio adequado de fazer contactos com outras organizações, de gerir as divergências e, no que respeita

\footnotetext{
${ }_{18}$ Ver, por exemplo, a opinião de duas das organizações feministas mais antigas, as Mulheres Comunistas Portuguesas (MCP) (http://www.pcp.pt/index.php?option=com_content\&task=view\&id =31701\&Itemid=195, consultado em 30/03/2009) e o Movimento Democrático de Mulheres (MDM) (http://www.mdm.org.pt/index.php?option=com_content\&task=view\&id=102\&Itemid=42, consultado em 30/03/2009).
} 
à interseccionalidade, de aumentar a sensibilização sobre as desigualdades múltiplas. Para o movimento LGTB, o seu significado é ainda maior, uma vez que é a primeira ocasião em que se vê representado num organismo oficial. Quando se pergunta sobre a existência de conflito, as respostas coincidem em assinalar a existência de uma certa tensão entre organizações. Curiosamente, longe de se considerar um facto negativo, afirma-se que quando se trabalha com entidades tão variadas, as divergências não só são esperadas como também desejadas. Apesar da aceitação tanto dos órgãos participativos como do alargamento da agenda, as vozes da sociedade civil destacam a necessidade de combater alguns perigos potenciais. Em primeiro lugar, defendem que é imprescindível manter as políticas e os organismos de igualdade especializados. Deve-se reconhecer, portanto, as características peculiares de cada eixo, evitando cair no que Verloo denominou a perspectiva one size fits all (2006). Também é preciso, apontam as respostas, ter em conta que abordar as desigualdades múltiplas pode significar estigmatizar grupos concretos. Isto coincide, assim, com o que se denominou o "dilema Crenshaw", isto é, dar visibilidade a um problema versus a possível estigmatização de um grupo (1993).

O nível de aceitação destacado da nova agenda política da igualdade, e em especial da emergente composição interseccional dos conselhos, não é, no entanto, casual. Muito pelo contrário, pode entender-se se tivermos em conta que as organizações da sociedade civil desenvolvem notáveis estratégias de cooperação desde o início da década, particularmente desde a realização do Fórum Social Português. Este evento funcionou como um ponto de inflexão, desencadeando a criação de fortes laços entre organizações e facilitando o trabalho conjunto (Santos, 2005). Este vê-se reflectido em numerosas actuações conjuntas - Orgulho LGTB, Marcha Mundial das Mulheres, etc. - e, especialmente, nas campanhas relativas a assuntos que geraram grande debate, como é o caso dos referendos sobre o aborto ou da regulamentação do casamento entre pessoas do mesmo sexo. Organizações de mulheres, sindicatos, movimento LGTB ou organizações de imigrantes estão, portanto, habituados a colaborar. Estes contactos "externos" tiveram, além do mais, incidência na maneira "interna" de abordar as desigualdades. Assim, várias organizações aumentaram a sua sensibilização sobre a sua própria diversidade, criando secções especializadas em abordar as desigualdades múltiplas dos seus próprios membros. ${ }^{19}$

${ }^{19}$ Ver, por exemplo, o Grupo GIRLS (Grupo para a Intervenção e a Reflexão sobre Lesbianismo) pertencente à ILGA-Portugal e o Grupo de Mulheres Imigrantes da associação Solidariedade Imigrante. A criação deste grupo teve muito que ver com a participação da associação na Marcha Mundial das Mulheres do ano 2005. 
Resta analisar se no futuro, tal como aponta a literatura, estes laços de colaboração entre organizações, assim como a presença de organismos participativos de composição crescentemente heterogénea, podem contribuir para o desenvolvimento de uma verdadeira visão interseccional nas políticas de igualdade portuguesas.

\section{Conclusões}

Este artigo procurou contribuir para a actual agenda de investigação relativa à introdução da interseccionalidade nas políticas públicas a nível nacional mediante a análise do caso português. A principal conclusão é que as políticas de igualdade começam a ser revistas, ainda que de modo limitado, com o objectivo de ter em consideração que as desigualdades nem sempre são totalmente independentes. Seguindo a tipologia apontada por Hancock, podemos argumentar, mais concretamente, que na actualidade se começa a transitar de uma perspectiva unitária em direcção a uma perspectiva múltipla. Por um lado, os organismos de igualdade e a principal normativa antidiscriminação continuam a abordar as desigualdades de modo essencialmente independente, aplicando políticas especializadas. Além disto, continua a existir um certo nível de hierarquia entre os eixos abordados, sendo o género, a deficiência e a raça os que contam com uma maior tradição e um maior desenvolvimento, e a orientação sexual a de mais recente introdução. Por outro lado, apesar desta abordagem unitária, existem certos aspectos que apontam para uma incipiente introdução de uma perspectiva múltipla. Primeiro, os principais planos de igualdade começam a admitir de modo explícito que as desigualdades múltiplas devem ser tidas em consideração. Segundo, estabelecem-se diversas estruturas interdepartamentais de coordenação dos diferentes organismos de igualdade, que, de agora em diante, devem trabalhar de maneira conjunta. Esta nova arquitectura institucional indica que Portugal está longe de adoptar o modelo integrado promovido pela UE, baseado na criação de um único organismo para todas as desigualdades. Na realidade, parece apostar em manter os "velhos" órgãos de igualdade, ainda que promovendo uma maior interligação entre eles. Este modelo, que podemos denominar de coordenado, pressupõe um desafio para a literatura sobre interseccionalidade, já que esta costuma abordar a arquitectura institucional de modo dicotómico - o modelo separado versus o modelo integrado, considerando este último como a única via para conseguir políticas que contemplem os indivíduos que se encontram nas intersecções. Finalmente, Portugal tem a peculiaridade de contar com uma longa tradição em matéria de criação de organismos participativos. Em linha com investigações prévias, este aspecto poderia contribuir para introduzir uma 
perspectiva interseccional que leve a que as desigualdades sejam tratadas como uma verdadeira questão empírica aberta - e política (open empirical and political-question). Em resumo, o caso português oferece diversas particularidades que contribuem para enriquecer o debate existente sobre a introdução da interseccionalidade nas políticas públicas e que abrem novas possibilidades para a sua implementação.

\section{Referências bibliográficas}

Abranches, Maria (2008), INTI Project: One-Stop Shop: A New Answer for Immigrant Integration? Country Report for Portugal. Lisboa: ACIDI.

Albuquerque, Rosana (2005), "Para uma análise multidimensional da situação das mulheres: as relações entre género, classe e etnicidade", in SOS Racismo (org.), Imigração e Etnicidade. Vivências e Trajectórias de Mulheres em Portugal. Lisboa: SOS Racismo, 37-49.

Alonso, Alba; Nunes, Inês (2008), QUING STRIQ Intersectionality Report: Portugal. Vienna: IWM.

Amâncio, Lígia (1998), "O feminismo português no final do século XX. Um olhar sobre o passado ausente e a promessa de futuro". Comunicação apresentada no Seminário sobre o Movimento Feminista em Portugal, organizado pela UMAR, 5-6 Dezembro, Lisboa.

Bell, Mark (2008), "The Implementation of European Anti-Discrimination Directives: Converging towards a Common Model?”, The Political Quarterly, 79(1), 36-44. Bento, Almerinda (1998), "Feminismo - o espaço para além da institucionalização". Comunicação apresentada no Seminário sobre o Movimento Feminista em Portugal, organizado pela UMAR, 5-6 Dezembro, Lisboa.

Bustelo, Maria (2009), "Spain: A Better Performer in Gender than in Intersectionality?", International Feminist Journal of Politics, 11(4), 530-546.

Capucha, Luís et al. (2005), "Portugal - A Virtuous Path towards Minimum Income?", in Maurizio Ferrera (org.), Welfare State Reform in Southern Europe: Fighting Poverty and Social Exclusion in Italy, Spain, Portugal and Greece. New York: Routledge, 205-265.

Cardoso, João Casqueira (2000), "Ethnicité et inégalité entre hommes et femmes au Portugal”, in Teresa Toldy e João Casqueira Cardoso (orgs.), A igualdade entre mulheres e homens na Europa às portas do século XXI. Porto: Universidade Fernando Pessoa, 229-246.

Crenshaw, Kimberlé (1989), "Demarginalizing the Intersection of Race and Sex: A Black Feminist Critique of Antidiscrimination Doctrine, Feminist Theory and Antiracist Politics", University of Chicago Legal Forum, 139-167.

Crenshaw, Kimberlé (1993), "Mapping the Margins: Intersectionality, Identity Politics, and Violence against Women of Color”, Stanford Law Review, 43, 1241-1299. 
Crenshaw, Kimberlé (2002), "Documento para o encontro de especialistas em aspectos da discriminação racial relativos ao gênero", Revista de Estudos Feministas, $10^{\circ}$ ano, $3^{\circ}$ trimestre, 171-188.

Donaghy, Tanhya Barnett (2004), "Mainstreaming: Northern Ireland's Participative-Democratic Approach”, Policy E Politics, 32(1), 49-62.

Ferreira, Virgínia (1998), “Os paradoxos da situação das mulheres em Portugal”, Revista Crítica de Ciências Sociais, 52/53, 199-227.

Hancock, Ange-Marie (2007), “When Multiplication Doesn't Equal Quick Addition: Examining Intersectionality as a Research Paradigm”, Perspectives on Politics, 5(1), 63-79.

Lombardo, Emanuela; Verloo, Mieke (2009a), "Institutionalising Intersectionality in the European Union? Policy Developments and Contestations", International Feminist Journal of Politics, 11(4), 478-495.

Lombardo, Emanuela; Verloo, Mieke (2009b), "Stretching Gender Equality to Other Inequalities: Political Intersectionality in European Gender Equality Policies", in Emanuela Lombardo et al. (orgs.), The Discursive Politics of Gender Equality. Stretching, Bending and Policymaking. London: Routledge, 154-188.

Mabbet, Deborah (2005), "The Development of Rights-based Social Policy in the European Union: The Example of Disability Rights", Journal of Common Market Studies, 43(1), 97-120.

Malheiros, Manuel (2007), Portugal: Country Report on Measures to Combat Discrimination, European Network of Legal Experts in the Non-Discrimination Field.

Nicholls, Kate (2007), Europeanizing Responses to Labour Market Challenges in Greece, Ireland and Portugal: The Importance of Consultative and Incorporative Policy-Making. Tese de doutoramento, Graduate School of the University of Notre Dame.

Niessen, Jan; Cormack, Janet (2004), "National Specialized Equality Bodies in the Wake of the EC Anti-discrimination Directives", in Janet Cormack (org.), Considerations for Establishing Single Equality Bodies and Integrated Equality Legislation. Report of the $7^{\text {th }}$ Experts' Meeting, hosted by the Equality Commission for Northern Ireland.

Rolandsen Agustin, Lise (2008), "Civil Society Participation in EU Gender Policy-Making: Framing Strategies and Institutional Constraints", Parliamentary Affaires, 61(3), 505-517.

Santos, Ana Cristina (2004), "Sexual Orientation in Portugal: Towards Emancipation", South European Society and Politics, 9(2), 159-190.

Santos, Ana Cristina (2005), A lei do desejo. Direitos bumanos e minorias sexuais em Portugal. Porto: Afrontamento.

Schmitter, Philippe C. (1975), Corporatism and Public Policy in Authoritarian Portugal. London: Sage.

Skjeie, Hege; Langvasbraten, Trude, (2009) "Intersectionality in Practice? Anti-Discrimination Reforms in Norway”, International Feminist Journal of Politics, 11(4), 513-529. 
Squires, Judith (2005), "Is Mainstreaming Transformative? Theorizing Mainstreaming in the Context of Diversity and Deliberation", Social Politics, 12(3), 366-388.

Squires, Judith (2007), “The Challenge of Diversity: The Evolution of Women's Policy Agencies in Britain”, Politics E Gender, 3(4), 513-530.

Squires, Judith (2008a), "Diversity mainstreaming: dépasser les approaches technocratiques et d'addition des inégalités", Cabiers du Genre, 44, 73-94.

Squires, Judith (2008b), "Intersecting Inequalities: Reflecting on the Subjects and Objects of Equality", The Political Quarterly, 79(1), 53-61.

Tavares, Manuela (2000), Movimentos de Mulheres em Portugal. Décadas de 70 e 80. Lisboa: Livros Horizonte.

Valiente, Celia (1998), "El feminismo de Estado en Portugal: La creación de la Comissão para a Igualdade e para os Direitos das Mulheres y su relación con el movimiento de mujeres", Comunicação apresentada no Seminário sobre o Movimento Feminista em Portugal, organizado pela UMAR, 5-6 Dezembro, Lisboa.

Verloo, Mieke (2006), "Multiple Inequalities, Intersectionality and the European Union", European Journal of Women's Studies, 13(3), 211-228.

Yuval-Davis, Nira (2006), "Intersectionality and Feminist Politics”, European Journal of Women's Studies, 13(3), 193-209. 